\title{
Left atrial global longitudinal strain predicts atrial fibrillation recurrence in patients with paroxysmal and persistent atrial fibrillation and preserved ejection fraction treated with first catheter ablation
}

\author{
Mislav Vrsalović1* \\ Scott L. Hummel ${ }^{2}$ \\ Hamid Ghanbari² \\ Craig Alpert ${ }^{2}$ \\ Hakan Oral ${ }^{2}$ \\ Theodore J. Kolias ${ }^{2}$ \\ 'University of Zagreb School \\ of Medicine, University \\ Hospital Centre "Sestre \\ milosrdnice", Zagreb, Croatia \\ Unniversity of Michigan \\ Cardiovascular Center, \\ Ann Arbor, Michigan, \\ United States of America
}

RECEIVED:

April 15, 2015

ACCEPTED:

April 20, 2015

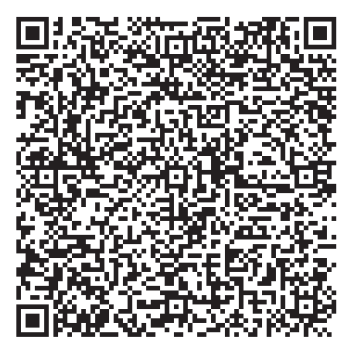

KEYWORDS: left atrial strain, left ventricular strain, atrial fibrillation, catheter ablation.

CITATION: Cardiol Croat. 2015;10(3-4):68. | DOI: http://dx.doi.org/10.15836/ccar.2015.68

ORCID: Mislav Vrsalović, http://orcid.org/0000-0002-8432-404X

*ADDRESS FOR CORRESPONDENCE: Mislav Vrsalović, Klinički bolnički centar Sestre milosrdnice, Vinogradska 29, HR-10000 Zagreb, Croatia. Phone: +385-1-3787-111. E-mail: mislav.vrsalovic@gmail.com

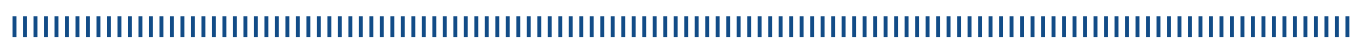

BACKGROUND: Atrial fibrillation (AF) frequently recurs after radiofrequency catheter ablation (CA). ${ }^{1-4}$ This study investigated novel echocardiographic strain parameters as predictors of outcome in AF treated with CA.

METHODS: 110 patients (pts, mean age 59, mean $\mathrm{CHA}_{2} \mathrm{DS}_{2}$-VASc $=1.37$ ) with paroxysmal and 92 pts (mean age 62 , mean $\mathrm{CHA}_{2} \mathrm{DS}_{2}-\mathrm{VASC}=1.5$ ) with persistent $\mathrm{AF}$ and preserved ejection fraction (EF) underwent $\mathrm{CA}$ and echocardiography $\leq 30$ days prior to CA. Left atrial (LA-GS) and left ventricular (LV-GS) global longitudinal strains were measured with 2D speckle tracking. Patients were followed for AF recurrence after CA.

RESULTS: During follow-up period (16 \pm 6 months for paroxysmal and 13 \pm 3 months for persistent AF), 44 (40\%) and $47(51 \%)$ pts had AF recurrence in each group. In both paroxysmal and persistent AF subgroup pts with AF recurrence had lower LA-GS (22\% vs 31\%; $\mathrm{p}<0.001$ and $11.3 \%$ vs $17.9 \%$; $<<0.001)$ and lower magnitude of LV-GS (-15.6\% vs $-17.4 \% ; \mathrm{p}=0.001$ and $-12.3 \%$ vs $-13.7 \% ; \mathrm{p}=0.007$ ). ROC analysis revealed that LA-GS predicted AF recurrence better than LV-GS or LAVI ( $p<0.01$ ). By multivariate analysis in paroxysmal AF subgroup, LA-GS entered either as a binary $(<24.5 \%)(\mathrm{HR}=8.91,95 \% \mathrm{CI}=4.35-18.27 ; \mathrm{p}<0.001)$ or a continuous variable $(\mathrm{HR}=0.88,95 \% \mathrm{CI}=0.85-0.92 ; \mathrm{p}<0.001)$ was the only independent predictor of AF recurrence. In the subgroup of pts with persistent AF, LA-GS (<11.98\%) (HR=5.50, 95\% CI=2.74-11.06; $\mathrm{p}<0.001)$ and LAVI $\left(>38 \mathrm{~mL} / \mathrm{m}^{2}\right)(\mathrm{HR}=2.28,95 \% \mathrm{CI}=1.26-4.13 ; \mathrm{p}=0.006)$ both entered as binary variables were independent predictors of AF recurrence. When echocardiographic parameters were analyzed as continuous variables LA-GS ( $\mathrm{HR}=0.82,95 \% \mathrm{CI}=0.75-0.88 ; \mathrm{p}<0.001$ ) was the only independent predictor of AF recurrence.

CONCLUSION: LA-GS using speckle tracking echocardiography is a strong and independent predictor of AF recurrence after first CA therapy in patients with paroxysmal and persistent AF and preserved EF.

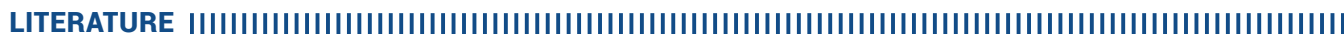

1. Zhuang J, Wang Y, Tang K, Li X, Peng W, Liang C, et al. Association between left atrial size and atrial fibrillation recurrence after single circumferential pulmonary vein isolation: a systematic review and meta-analysis of observational studies. Europace. 2012;14(5):638-45. DOI: http://dx.doi.org/10.1093/europace/eur364

2. Shin SH, Park MY, Oh WJ, Hong SJ, Pak HN, Song WH, et al. Left atrial volume is a predictor of atrial fibrillation recurrence after catheter ablation. J Am Soc Echocardiogr. 2008;21(6):697-702. DOI: http://dx.doi.org/10.1016/j.echo.2007.10.022

3. Kuppahally SS, Akoum N, Burgon NS, Badger TJ, Kholmovski EG, Vijayakumar S, et al. Left atrial strain and strain rate in patients with paroxysmal and persistent atrial fibrillation: relationship to left atrial structural remodeling detected by delayed-enhancement MRI. Circ Cardiovasc Imaging. 2010;3(3):231-9. DOI: http://dx.doi.org/10.1161/CIRCIMAGING.109.865683

4. Morris DA, Parwani A, Huemer M, Wutzler A, Bekfani T, Attanasio P, et al. Clinical significance of the assessment of the systolic and diastolic myocardial function of the left atrium in patients with paroxysmal atrial fibrillation and low CHADS(2) index treated with catheter ablation therapy. Am J Cardiol. 2013;11(7):1002-11. DOI: http://dx.doi.org/10.1016/j.amjcard.2012.12.021 